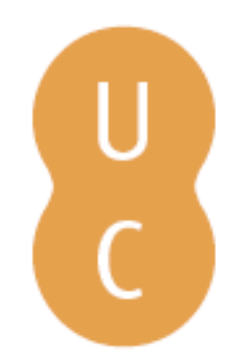

\title{
nombalina
}

\section{Compartilhando experiências artístico-culturais no âmbito da saúde mental no Brasil: traços clínicos e a produção de novos diálogos e práticas}

\author{
Autor(es): $\quad$ Castro, Eliane Dias de \\ Publicado por: Imprensa da Universidade de Coimbra \\ URL \\ persistente: URI:http://hdl.handle.net/10316.2/35960 \\ DOI: $\quad$ DOI:http://dx.doi.org/10.14195/978-989-26-0852-5_7 \\ Accessed : $\quad$ 26-Apr-2023 11:56:49
}

A navegação consulta e descarregamento dos títulos inseridos nas Bibliotecas Digitais UC Digitalis, UC Pombalina e UC Impactum, pressupõem a aceitação plena e sem reservas dos Termos e Condições de Uso destas Bibliotecas Digitais, disponíveis em https://digitalis.uc.pt/pt-pt/termos.

Conforme exposto nos referidos Termos e Condições de Uso, o descarregamento de títulos de acesso restrito requer uma licença válida de autorização devendo o utilizador aceder ao(s) documento(s) a partir de um endereço de IP da instituição detentora da supramencionada licença.

Ao utilizador é apenas permitido o descarregamento para uso pessoal, pelo que o emprego do(s) título(s) descarregado(s) para outro fim, designadamente comercial, carece de autorização do respetivo autor ou editor da obra.

Na medida em que todas as obras da UC Digitalis se encontram protegidas pelo Código do Direito de Autor e Direitos Conexos e demais legislação aplicável, toda a cópia, parcial ou total, deste documento, nos casos em que é legalmente admitida, deverá conter ou fazer-se acompanhar por este aviso.

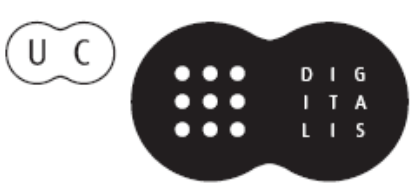





\section{COMPARTILHANDO EXPERIENCIASARTÍSTICO- -CULTURAIS NO ÂMBITO DA SAÚdE MENTAL NO BRASIL: TRAÇOS CLÍNICOS EA PRODUÇÃo DE NOVOS DIÁLOGOS E PRÁTICAS}

Três movimentos marcados por uma aproximação com o campo das artes inovaram o cenário da Saúde Mental no Brasil. Nise da Silveira, nos anos 1940, observou cuidadosamente pessoas com sofrimento psíquico para estruturar ateliês artísticos. Ao acolher questões singulares, possibilitou às pessoas atendidas darem forma à dor do inarticulado e colocarem no mundo matérias de expressão. A partir dos anos 1980, com o começo das práticas psiquiátricas baseadas na Reabilitação Psicossocial, propostas com arte constituíram iniciativas contra o isolamento e a solidão, recuperando direitos e a cidadania dos pacientes. Na década de 1990, na Universidade de São Paulo, práticas, formação e pesquisas validaram um campo em composição, interconectando conhecimentos para mobilizar na Terapia Ocupacional novas tecnologias de cuidado e participação sociocultural. Diferentes linguagens artísticas estabelecem relações com a construção do cotidiano, a produção de subjetividades e a renovação do território sociocultural, ampliando a participação das populações em vulnerabilidade social.

\footnotetext{
${ }^{1}$ Prof. ${ }^{\text {a }}$ Dra. do Departamento de Fisioterapia, Fonoaudiologia e Terapia Ocupacional. Faculdade de Medicina da Universidade de São Paulo, Brasil. E-mail: elidca@usp.br
} 


\section{Introdução}

Agradeço o convite da organização do Congresso e a oportunidade de compartilhar com vocês algumas experiências artístico-culturais brasileiras que surgiram e continuam surgindo no âmbito da Saúde Mental, trazendo indagações e reflexões e propiciando novas práticas e a ampliação das ações para a construção dos direitos das pessoas que vivem grande sofrimento psíquico. Apresento três movimentos que inovaram o cenário da Saúde Mental no Brasil, marcados por uma aproximação com o campo das artes e da cultura.

Remontando um percurso histórico, começo falando sobre os ateliês artísticos de Nise da Silveira e em sua contribuição para a vida das pessoas atendidas no âmbito da assistência psiquiátrica, que imprimiu transformações nas práticas vigentes entre os anos 1930 e o final dos 1970, no Brasil. Depois, faço um breve esboço do movimento brasileiro de desinstitucionalização psiquiátrica, ocorrido a partir dos anos 1980, da implantação de novas políticas de saúde mental, apontando a renovação de conceitos e práticas e a multiplicação de projetos artísticos para as pessoas atendidas em psiquiatria e saúde mental, e de sua ampliação, no final dos anos 2000, para atender às populações em vulnerabilidade social, com a criação de muitos projetos com arte nos equipamentos de atenção e de desenvolvimento socioculturais (os centros de atenção psicossocial, os centros de convivência e cooperativa e os projetos artísticos específicos nesse âmbito). Por fim, trago exemplos do que vimos produzindo atualmente, em especial na Universidade de São Paulo, onde esferas de conhecimento articulam para alimentar novas práticas e mobilizar na Terapia Ocupacional contemporânea novas tecnologias de cuidado e de participação sociocultural, nos quais as artes plásticas e as artes do corpo são pivôs para a renovação do cotidiano e a construção de redes de participação social.

Esse percurso é acompanhado de imagens, para que também possamos produzir coletivamente uma experiência de recepção artística cuja qualidade das produções abre nas sensibilidades uma experiência estética, imprimindo um certo "estado de arte". São imagens de formas objetivamente configuradas, produzidas no campo clínico ou em ateliês 
artísticos, que acolhem a população psiquiátrica e criam aberturas para a construção da saúde mental. O intuito é promover uma determinada recepção que tem em si um valor estético. A apreciação estética é uma qualidade que nos afeta, compreende e vai além dos sentimentos, das emoções e das sensações, provocando satisfação ou insatisfação, familiaridade ou estranhamento, compreensão ou incompreensão, fluxos, desestabilização, deslocamentos e cenários da alteridade.

Podemos pensar que a apreciação estética produz "estados de arte" em que nos deixamos tomar por estados intensos: o desassossego, o estranhamento, as situações paradoxais, o encantamento, o trágico, a expansão da vida. Para Rolnik (1996), a obra sabe alguma coisa que eu não sei, e "esta se dá na produção de diferenças e sua afirmação em novas formas de existência" (Rolnik, 1996, p. 44).

\section{A contribuição de Nise}

Em meados de 1930, a psiquiatra Nise da Silveira iniciou seu trabalho no Centro Psiquiátrico Pedro II, no Rio de Janeiro, quando a psiquiatria hegemônica brasileira tinha toda a sua atenção voltada para tratamentos com eletrochoques e cirurgias neurológicas. Depois, em torno dos anos 1950, o uso intensivo de neurolépticos inscreveu nas práticas psiquiátricas do país uma visão estritamente orgânica da doença mental. Nise se opôs frontalmente a tais procedimentos e encetou um embate contra a psiquiatria de seu tempo. Para ela, a vida psíquica deveria ser pensada como processo constante de interação com aquilo que cerca cada ser humano. Entendida numa dimensão fenomenológica, a psicopatologia consistiria em planos de experiência, em modos de ser e de estar no mundo.

Movida por sua indignação com o tratamento oferecido aos pacientes dos hospitais psiquiátricos no Rio de Janeiro, Nise investiu na pesquisa e no desenvolvimento de uma prática clínica em terapia ocupacional, com o compromisso de criar procedimentos terapêuticos de caráter humanista para o tratamento da esquizofrenia. Para estruturar os ateliês de trabalho artístico, observou cuidadosamente pessoas com doença mental que 
demonstravam intenso sofrimento psíquico. Seu interesse era penetrar no mundo interno dos esquizofrênicos, aproximar-se deles, conhecer-lhes a dor e, ao mesmo tempo, melhorar suas condições de vida. Buscou construir uma terapia ocupacional com características científicas, imprimindo ao trabalho uma orientação própria: sua preocupação era de natureza teórica e clínica (Castro \& Lima, 2007).

Nos atendimentos, ela procurava criar um clima de liberdade, sem coação, no qual, por meio de diversas atividades, os sintomas pudessem se expressar e, como ela dizia, ser despotencializados. Desenvolveu progressivamente 17 núcleos de atividades: encadernação, marcenaria, trabalhos manuais, costura, música, dança, teatro, festas e comemorações, entre outros, em que oferecia atividades que fortalecessem os pacientes, promovessem a progressiva ampliação de seu contato com o meio social e servissem como forma de expressão (Castro \& Lima, 2007).

Os ateliês atraíam pessoas com experiências cotidianas vazias, empobrecidas e sem sentido. Poucos pacientes os frequentavam, talvez pela "não aceitação pelos psiquiatras das ocupações como agentes terapêuticos" (Silveira, 1981, p. 24).

Detenho-me num dos principais núcleos de atividades, o ateliê de pintura, construído em colaboração com o artista plástico brasileiro Almir Mavignier e organizado como um espaço onde os pacientes podiam passar muito tempo pintando livremente, não havia aulas, propriamente, mas antes conselhos técnicos. Não havia reprodução de obras ou livros e revistas de arte, para se preservarem as imagens do inconsciente. Nise afirmava que todas as atividades do Setor de Terapêutica Ocupacional eram expressivas, mas, nos frequentadores do ateliê de pintura, havia "uma pulsão configuradora de imagens sobrevivendo mesmo quando a personalidade estava desagregada" (Silveira, 1992, p. 63).

A experiência do ateliê mostrou as fontes de criação que estão dentro, e não fora do artista. Os pintores trabalhavam muito concentrados e pintavam quase diariamente, o que os fazia melhorar tecnicamente. Nesses ateliês, formou-se um grupo de pintores que encontrou aí um lugar de produção: os artistas de Engenho de Dentro, com uma produção artística incomparável na história da arte moderna do Brasil, porque, por um lado, 
eles eram um núcleo de expressão que causava impacto e perplexidade, com obras que fundiam imagem e linguagem, e, por outro, não foram influenciados por movimentos artísticos hegemônicos do sistema de arte ou por tendências internacionais.

Nas palavras de Palatinik, outro artista brasileiro que participou dessa experiência:

Até hoje me surpreendo, enfim, com a eloquência dos princípios estéticos dos artistas de Engenho de Dentro e com a incontestável autenticidade e beleza de seus trabalhos. Por não estar contaminados com tendências, influências, receitas e teorias, e a despeito de sua esquizofrenia - e mesmo de certa forma beneficiados por ela, porque não dizer? -, estavam livres para usar em suas obras aquela fantástica, poderosa e até então aprisionada riqueza de vivência e imagens, com seus símbolos e arquétipos emergindo do inconsciente com força, superioridade e presença suficientes para suprir a necessidade vital de comunicar! (Palatnik, A., 2000, p. 240).

\subsection{A trama moderna e os artistas de Engenho de Dentro}

A colaboração entre Nise e Almir Mavignier reuniu um grupo de críticos e artistas do Rio de Janeiro que, no final da década de 1940 e no decorrer da seguinte, foram profundamente afetados pela produção artística dos internos de Engenho de Dentro e também responsáveis pela criação do Museu de Imagens do Inconsciente e pela revelação de pintores de grande talento. Emydio de Barros, Carlos Pertuis, Fernando Diniz e Adelina são exemplos de artistas que emergiram desse encontro.

Para os críticos de arte brasileiros que a conheceram e acompanharam seu trabalho, essas produções evidenciam uma marca modernista na produção artística do Museu. Neles se percebe um deslocamento movido pela arte moderna: abandonando a noção de arte como representação e lembrando-nos de Cézanne, põem-nos em contato com matérias que são da ordem da sensação. Para Rolnik (2002, p. 4), o artista moderno sai do estatuto de gênio, demiurgo, apartado do mundo e com a missão de ordená-lo. 
Numa revolução de valores, o artista moderno toca uma perspectiva afetiva, que imprime ao processo de criação um "ritmo poético" e plástico mais sensível às formulações interiores, às aspirações íntimas [...] " $a$ arte, para ser arte, é de início uma questão de emoção e sensação [...] sensação e revelação" (Pedrosa, 1949, p. 150/153).

Para Mário Pedrosa, um importante crítico de arte, a perplexidade e o estranhamento que do contato com as obras expostas no Museu tocam tanto o público comum quanto a vanguarda artística. Isso comprovava a sua hipótese de que a atividade artística não depende, pois, de leis estratificadas, frutos da experiência de determinada época da história da arte. Essa atividade se estende a todos as pessoas e não é mais ocupação exclusiva de uma confraria especializada que exige formação específica. (Pedrosa, 1949, p. 150): “A arte é uma necessidade vital. O fenômeno artístico abre uma experiência de vitalidade, ou forma de vitalidade [...] são vitaminas da alma a luz, a cor, o ritmo, a forma, o movimento, a proporção" (Pedrosa, 1949, p. 164).

Para ele, o contato com essas obras leva a uma experiência de desprendimento de partes de que as pessoas habitualmente se esquecem, a uma exteriorização de sensações que acabam confundindo a própria realidade, como objetos que não pertencem mais ao mundo consciente, com estruturas inacabadas, informes, descoordenadas, de uma qualidade "esquisita". Nada isso impede que numa trama caótica se revelem ao olhar atento detalhes admiráveis, vagas sugestões de sonhos, matéria bruta emotiva da criação formal, alma da composição com forças explosivas necessárias à criação (Pedrosa, 1949, 157-159). Por outro lado, numa perspectiva clínica, Nise acreditava que, para acompanhar a produção criativa dos pacientes, era preciso ter paciência e tato, e não apressar as coisas. Ela reconhecia a força e a fragilidade da obra quando vinha ao mundo e sentia-se guardiã de seu processo de criação, sempre atenta à vitalidade da criação, cuja força, beleza e estranhamento impactavam. A psicologia junguiana, a literatura, a arte e a mitologia instrumentalizaram-na para a compreensão das metamorfoses do ser e para a investigação da incansável trajetória do homem em busca de seu mito. 
Com esses estudos, Nise apresentou uma compreensão da psique como um sistema vivo, com dinâmica própria, que se autorregula e se direciona para a cura e para a saúde. Além disso, criou um método para a leitura das imagens que emergiam na produção artística dos pacientes que participavam dos ateliês de pintura e modelagem do Engenho de Dentro. A vida e a obra de alguns deles retratam efetivamente a força dessa experiência.

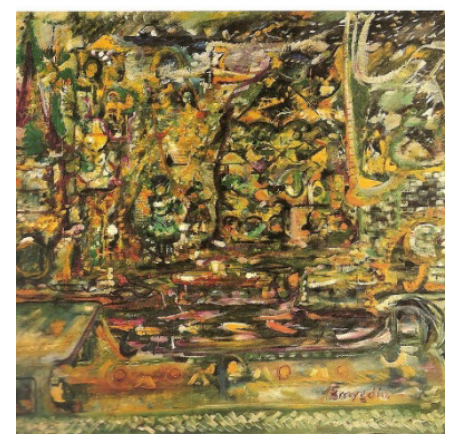

Emygdio de Barros.

Ilíada (1948)

Óleo sobre tela

Museu de Imagens do Inconsciente - RJ

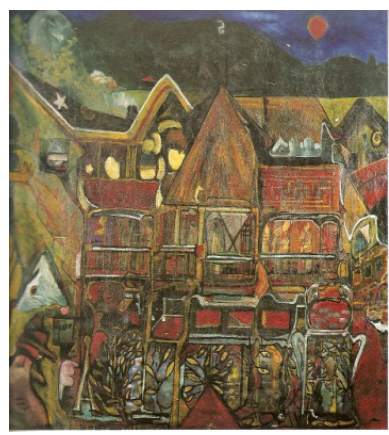

Emygdio de Barros.

Casa de São Cristóvão (1949)

Óleo sobre tela

Museu de Imagens do Inconsciente - RJ

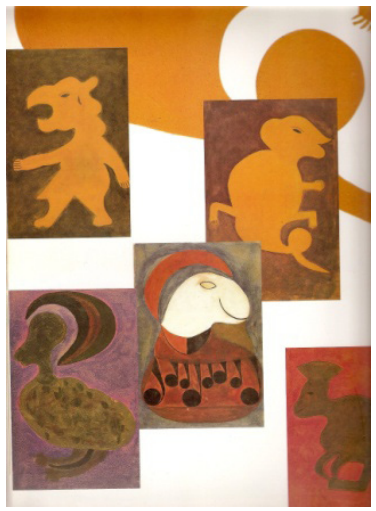

Painel Animais Fantásticos

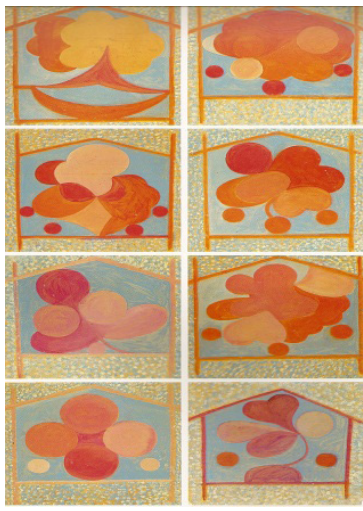

Painel Formas e Transformações

Carlos Pertuis

Óleo e guache sobre papel

Museu de Imagens do Inconsciente - RJ 


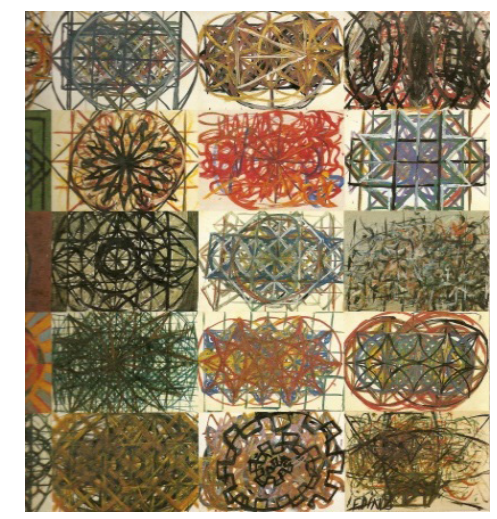

Painel Caos Mandala

Fernando Diniz

Óleo e guache sobre papel

Museu de Imagens do Inconsciente - RJ

\subsection{Diálogos críticos e repercussão}

Nise foi surpreendida pela quantidade de trabalhos produzidos e pela manifestação de criatividade que resultava na produção de pinturas em número incrivelmente grande, num contraste com a pouca atividade de seus autores fora do ateliê. A qualidade de muitos desenhos, pinturas e modelagens fascinava e entusiasmava. A presença de artistas contribuía para dar ao espaço um caráter de verdadeiro ateliê de pintura; eles colaboravam com conhecimentos técnicos sobre os materiais e também com sua sensibilidade estética, produzindo pequenas intervenções para não tolher a expressão livre. Foram eles que montaram e ordenaram as primeiras séries de desenhos e pinturas. O número e a qualidade dos trabalhos os levaram a organizar a primeira exposição dessas produções em 1947, no Rio de Janeiro. Posteriormente, com a intervenção de críticos de arte, a exposição foi levada ao Museu de Arte de São Paulo (Masp).

Os críticos de arte se mostraram muito atentos à produção plástica dos internos do Engenho de Dentro e, por essa perspectiva, Nise priorizou o valor artístico dos trabalhos, contrapondo-se à ideia de uma "arte psico- 
patológica”, em que se procuram sintomas e reflexos de ruína psíquica. A psiquiatra sempre se absteve de se posicionar sobre a qualidade estética dos trabalhos produzidos no ateliê, deixando essa tarefa para os críticos e dedicando-se ao estudo científico dos problemas que essa produção levantava. No entanto, via com naturalidade a possibilidade de que entre os pacientes houvesse aqueles com capacidade artística. Nise criou o Museu de Imagens do Inconsciente com o intuito de organizar e catalogar esse material com critério e cautela - o que permitiria o desenvolvimento de uma série de pesquisas em torno dessas imagens.

Numa iniciativa inédita para a cultura brasileira e envolvendo artistas e críticos de arte no processo, Nise recorreu a um tratamento museográfico das obras dos pacientes. Mantendo-se sempre no campo da psiquiatria, não deixou de buscar parcerias no campo das artes, demonstrando uma excepcional capacidade de articulá-los, estabelecendo muitos diálogos interdisciplinares (Castro \& Lima, 2007).

A psiquiatra e sua equipe deparavam-se com problemas sempre mais complexos: como ajudar os artistas revelados no Engenho de Dentro, propiciando-lhes um futuro menos trágico e, ao mesmo tempo, preservar suas obras? Nesses termos, o Museu teria que ser também um abrigo, um lugar para acolher a criação. Assim, os trabalhos produzidos nos ateliês e suas exposições também eram armas de combate ao manicômio e ao tratamento psiquiátrico hegemônico, aliadas na luta pela transformação cultural de certa concepção de loucura e enlouquecimento. O Museu tem cerca de 350 mil obras e ainda tem um papel importante na transformação cultural em direção a uma sociedade mais tolerante, que pode se enriquecer com suas diferenças.

Nesse percurso do psíquico ao artístico, o que Nise propõe não é só uma leitura arquetípica das produções artísticas, embora ela seja predominante, mas uma leitura do psíquico pelos mecanismos de constituição da arte: "a vontade de formar o mundo é muito mais profunda nas expressões do inconsciente" (Frayze-Pereira, 1995, p. 15).

A leitura da obra proposta por Nise e realizada na organização artística do Museu se incorporou à história dessas produções, constituindo-as e instaurando um trabalho concreto de reflexão sobre elas. O cuidado e a 
delicadeza na organização e manutenção dessas produções favoreceram uma contemplação que, além de transcender a clínica, presenteou, por meio das exposições, o público mais amplo, abrindo um percurso dessas produções em nossa cultura. Esses gestos criaram, sadiamente, um caminho de reconhecimento dessas produções e uma experiência sensível no âmbito coletivo que multiplica as formas de compreensão e os pontos de vista dessa análise (Castro \& Lima, 2007).

Sua atenção na construção de ambientes propícios à criação levou-a a trabalhar também na organização dos espaços e tempos institucionais e na formação dos profissionais que acompanhavam os pacientes. Para ela, para que qualquer atividade viesse a ter uma função terapêutica, era preciso que fosse desenvolvida num ateliê acolhedor que, independentemente do ambiente hospitalar em que se inserisse transformava-se em espaço significativo, desencadeador de aproximações e contatos disruptores do processo de criação. Esses ateliês eram preparados pelos monitores de forma a dar continência aos internos, acolhendo dores, silêncios e ritmos e, ao mesmo tempo, estimulando a expressão. A presença constante de um monitor visava não a interferência nos trabalho dos pacientes, mas a disponibilidade de um afeto catalisador que lhes estimulasse a criatividade e permitisse restaurar formas de comunicação com o mundo. Nise adotou o conceito de afeto de Spinosa, como um afeto que seria produzido por um bom encontro, e o associou à ideia de um disparador do processo de cura - tomando da química a ideia de catalisador, substância que acelera reações. Acreditava que o processo terapêutico devia ser acompanhado de forma adequada, cuidadosa e atenta, com a presença e a sensibilidade humanas para perceber e observar as expressões e manifestações dos pacientes, fundamentais para dar continência às experiências, para não apressar as coisas e para estimular processos de criação que só poderiam evoluir se, no ambiente em que vivesse, o paciente encontrasse o suporte do afeto. Dizia ela: "dificilmente qualquer tratamento será eficaz se o doente não tiver a seu lado alguém que represente um ponto de apoio no qual ele faça investimento afetivo" (Silveira, 1981, p. 68). 
Nesse sentido, valorizava a pessoa do monitor, sua sensibilidade e intuição, o que favoreceria uma experiência artística potente. No entanto, mesmo considerando que as teorias valem menos que "o esforço impregnado de simpatia para penetrar no mundo interior do doente" (Silveira, s/d, p. 18), a formação do monitor foi sempre uma questão fundamental. Para Nise, essa formação devia ser contínua, compreendendo conhecimentos em várias áreas, da psiquiatria e psicologia à mitologia, arte e antropologia. O objetivo era que os monitores compreendessem o processo psicótico e o processo de cura posto em marcha pela atividade artística e fizessem conexões entre as imagens produzidas, a situação emocional do interno e as produções culturais de outras épocas e outros lugares, pelo estudo de séries de imagens. Nise formou profissionais de diversas áreas do conhecimento, efetivando uma experiência interdisciplinar.

Em 1956, criou a Casa das Palmeiras, precursor de passagem indispensável entre o hospital psiquiátrico e o meio social. O principal método empregado na Casa foi a terapia ocupacional, realizada, segundo Nise, num amplo sentido:

Visamos coordenar intimamente olho e mão, sentimento e pensamento, corpo e psique, primeiro passo para a realização do todo específico que deverá vir a ser a personalidade de cada indivíduo sadio. Na busca dessa coordenação, fazemos apelo às atividades que envolvam a função criadora existente, mais ou menos adormecida, dentro de todo indivíduo (Silveira, 1986, p. 11).

O trabalho de Nise da Silveira, de grande sensibilidade e delicadeza, abriu espaço para manifestações e criações consideradas "loucas" e afirmou a importância de uma escuta atenta e interessada por essas produções, provocando um profundo processo de resistência, inovação e transformação cultural. Assim, a questão terapêutica ganhou um lugar de relevância, chegando a superar a função diagnóstica. A inovação clínica se deu por meio de experimentação, invenção, criatividade, afeto, cuidado, compreensão e construção de passagens para a autonomia (Castro \& Lima, 2007). 


\section{A reabilitação psicossocial e práticas artístico-culturais nesse contexto}

As transformações ocorridas a partir da vinda de Franco Basaglia ao Brasil, no início dos anos 1980, criaram um movimento de abertura das práticas psiquiátricas, cujas re-estruturações basearam-se nos movimentos de desinstitucionalização psiquiátrica e na Reabilitação Psicossocial. Denúncias sobre a vida e o cuidado de pessoas em instituições totais como os manicómios conectaram-se aos movimentos dos trabalhadores em saúde mental, instaurando uma ampla discussão sobre a loucura, desmontando os aparatos institucionais que impossibilitavam a existência humana, transformando os modos como se tratavam as pessoas, e dando novos rumos para a atenção em saúde mental. Configurou-se neste período uma história repleta de lutas, de enfrentamento de barreiras e impedimentos, um movimento vivo e repleto dos trabalhadores de saúde mental, que imprimiu na atenção psiquiátrica brasileira, importantes revisões de conceitos e práticas.

No final dos anos 1980, com a implantação das diretrizes políticas para a atenção em saúde mental e a invenção de novas instituições, já havia muitas propostas com arte para as pessoas atendidas, que integraram iniciativas concretas contra o isolamento e a solidão, construídas em outra perspectiva, a de recuperar os direitos e a cidadania dos pacientes e a de atuar como motores de produção de contextos, relações e novos instrumentos de vida. Nesse processo gradual, o conceito de reabilitação adquiriu significações diferentes e complexas e níveis diversos de ações, mais eficazes na transformação da vida dos pacientes, e passou a fazer parte do cotidiano dos profissionais. As novas noções de reabilitação se preocupavam com a criação de propostas de vida para os pacientes, apresentaram ações ligadas ao tratamento e à transformação concreta da vida e concorreram para a reconstrução da cidadania plena, de direitos substanciais. Isso criou uma demanda de transformação cultural nas práticas em saúde e nas relações sociais.

A direção implementada nos processos de reabilitação, que consiste em trabalhar no sentido de aumentar a tolerância social, depende de lutas 
conduzidas para discutir e ampliar os direitos dos pacientes e dinamizar os fenômenos de inclusão/exclusão. Cronificação e exclusão não são produtos da doença, mas de uma constelação de variabilidades que podem ser modificadas e orientadas na intervenção. São muitas vezes variáveis ligadas ao contexto microssocial (família e comunidade) e pressupõem estratégias de gerenciamento ambiental bem distintas das estratégias propostas pelo modelo biomédico (Saraceno, 1995, p. 11).

\subsection{Arte contemporânea, intervenções pós-modernas e a crítica de arte}

Foi no fogo deste movimento que equipes de saúde mental responsáveis pela avaliação das condições sanitárias de grandes hospitais psiquiátricos, e também, artistas, críticos de arte, curadores e toda a sociedade brasileira, puderam entrar em contato com aspectos muito peculiares do processo criativo de Bispo do Rosário, um homem internado num hospício do Rio de Janeiro, durante 50 anos (de 1939 até 1989).

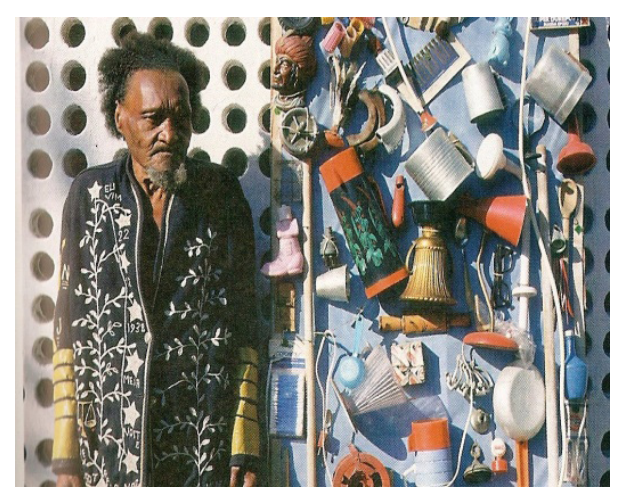

Arthur Bispo do Rosário

(1909-1989)

No início dos anos 1980, Bispo do Rosário, começou a sair do anonimato. Sua história foi contada em cadeia nacional pela televisão, virou protagonista de um filme, e no final da década, após sua morte, foi celebrado como artista em exposições internacionais. 
Bispo compôs uma trajetória bastante peculiar - seus dados biográficos por vezes se esvaem entre verdade e fantasia. Ele viveu num mundo paralelo. O que os médicos classificariam como delírio místico, Bispo traduziria como desígnios da fé. Uma devoção que resultou em quase mil obras, ao longo da vida. Em parte feito com sucata do hospício, seu mundo particular foi catalogado como obra de arte (Hidalgo, 1996, p. 8).

Em 1982, o Museu de Arte Moderna do Rio de Janeiro expôs pela primeira vez alguns exemplares de seu universo. A mostra "À margem da vida" juntou numa mesma exposição trabalhos de presidiários, menores infratores, idosos institucionalizados e loucos. Bispo se destacou, pois se fazia representar por grandes estandartes bordados, signos de uma arte contemporânea colhidos na sucata de um hospício.

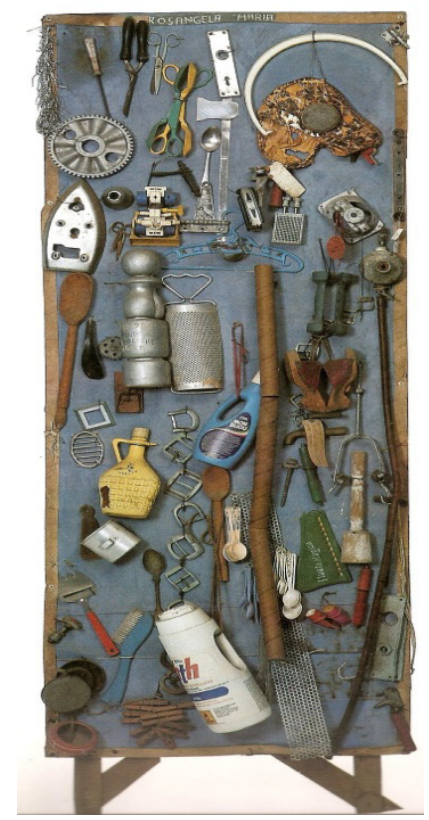

\section{Bispo de Rosário Bolsa de gelo}

Montagem com bolsa de gelo e objetos de madeira, ferro e plástico sobre suporte de madeira, ferro e papelão

Museu Nise da Silveira - Colónia Juliano Moreira, RJ 


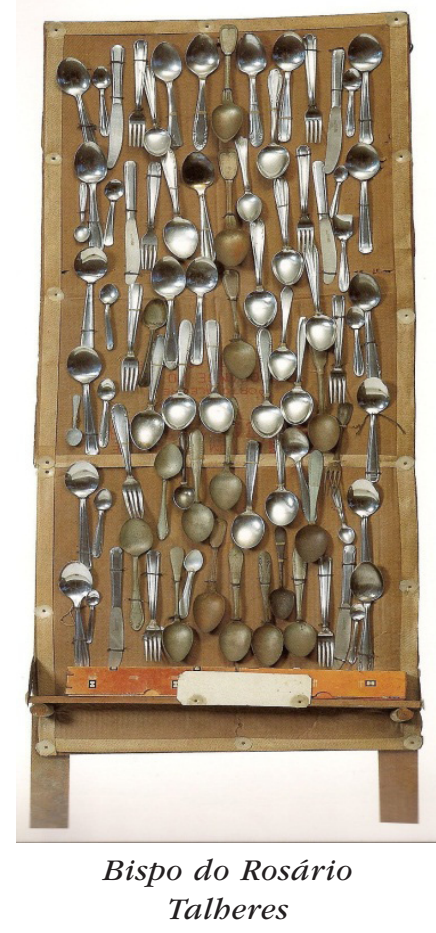

49 colheres de sopa, dez colheres de chá, quatro de café e cinco de sobremesa, dez garfos, seis facas em metais variados e duas caixas de papelão, plástico, pregos, fita de tecido e fórmica. Museu Nise da Silveira - Colónia Juliano Moreira - RJ

Bispo driblou eletrochoques, lobotomias e remédios, impôs-se como xerife do núcleo Ulisses Viana e fez do asilo sua trincheira. No silêncio da clausura, orquestrou assemblages, estandartes e objetos. Desfiou os uniformes do hospício para seus bordados e escreveu sem descanso (Hidalgo, 1996, p. 9).

Sua obra criou grandes indagações: ficava difícil de entender como Bispo fora capaz de erguer um império de formas e cores amarrado à rotina do asilo. Ele não coube nesta paisagem árida. Não abria mão da criação por nada. Seu trabalho era visceral.

Sua obra continha as raízes culturais de sua cidade natal, um povoado católico do nordeste do país, com tradição nos bordados, um dos pólos de produção e exportação dessa arte na região. Bispo resgataria o dom 
herdado e bordaria sem parar até os últimos anos de sua vida, ou até quando o cansaço minasse a sua visão (Hidalgo, 1996, p. 9).

Repetidas vezes se recusou a expor sua obra em galerias. Alheio às vertentes plásticas mundiais, não desgrudava de seu trabalho, que considerava um rito sagrado ditado por anjos. Não queria que seu templo caísse em desgraça. A obra era a vida, a vida era a obra. Só depois de muita negociação, contratos e garantias, ele determinou o que podia ser apresentado ao mundo. Tratava as obras como filhos: conversava com elas e cultivava rituais de cuidado. Críticos de arte brasileiros the ofereceriam espaços expositivos importantes, e Bispo declinava (Hidalgo, 1996, p. 153).

Depois de sua morte, o crítico de arte e entusiasta de sua obra Frederico Morais organizou a primeira exposição de seus trabalhos na Escola de Artes Visuais do Parque Lage, em 1989. A mostra teve grande sucesso de público e crítica, e a obra de Bispo transpôs as fronteiras do hospício, do Rio de Janeiro e do Brasil, chegando à Europa, onde, em 1995, participou da XLVI Bienal de Veneza, sempre despertando surpresa e admiração. O Centro George Pompidou, em Paris, e o Whitney Museum, de Nova York, pediram obras suas para exposição. Hoje, o Museu Nise da Silveira, no Rio de Janeiro, reúne o acervo de Arthur Bispo do Rosário.

Para Frederico Morais, Bispo do Rosário difere dos artistas do Engenho de Dentro por atuar no campo tridimensional - ele sempre fez objetos e textos. Nesse sentido, podemos dizer que os artistas de Engenho de Dentro estão para o Impressionismo, o Cubismo, o Expressionismo e a Arte Abstrata assim como Bispo está para a Pop Art, o Novo Realismo, as tendências arqueológicas, a nova escultura e até a arte conceitual. Se os primeiros são modernos, Bispo é pós-moderno (Hidalgo, 1996, p. 155).

Enquanto os artistas do Engenho de Dentro recebiam papel, tinta, incentivo, ateliês, Bispo contava com estímulos próprios e de uma outra dimensão. E Frederico Moraes iria mais além, via em sua obra um trânsito no território da arte de vanguarda, do dadaísmo, de Marcel Duchamp.

No acervo nacional, seus mantos e peças de vestuário lembram os parangolés de Helio Oiticica, e suas faixas das misses, Rubens Gerchman (Hidalgo, 1996, p. 156). É o único artista brasileiro referido no Museu de Arte Bruta de Lausanne. 
Para Rolnik (2002, p. 4), podemos associar sua produção artística à arte contemporânea, que leva mais longe a virada da arte moderna: se esta não representa o mundo a partir de uma forma que lhe é transcendente, mas, em vez disso, decifra e atualiza as transformações do mundo a partir das sensações, e o faz na própria imanência da matéria, o artista contemporâneo amplia o trabalho com a matéria do mundo, indo além não só dos materiais tradicionalmente trabalhados pela arte, mas também de seus procedimentos (escultura, pintura, gravura etc.): ele toma a liberdade de explorar os mais variados materiais e de inventar o método apropriado para cada tipo de exploração.

Portanto, na contemporaneidade, um dos aspectos que mudam é que, ao trabalhar qualquer matéria do mundo e nele interferir diretamente, explicita-se de modo mais contundente que a arte é uma prática de problematização (decifração de signos e produção de sentido), de interferência direta no mundo. É exatamente nessa interferência na cartografia vigente que a prática estética faz obra, sendo o bem-sucedido da forma indissociável de seu efeito problematizante (Rolnik, 2002, p. 4).

$\mathrm{O}$ mundo se liberta de um olhar que o reduz às suas formas constituídas e à sua representação para se oferecer como campo trabalhado pela vida como potência de variação e, portanto, em processo de engendramento de novas formas. A arte participa da decifração dos signos das mutações sensíveis, inventando novas formas através das quais tais signos ganham visibilidade. A arte é, portanto, uma prática de experimentação que participa da transformação do mundo (Rolnik, 2002 p. 4).

Definitivamente, a obra de Bispo abriu no campo da saúde mental brasileira muitas possibilidades de experimentação contemporânea em arte, nas quais as práticas estéticas abraçam a vida como potência de criação nos diferentes meios em que ela opera, sendo seus produtos uma dimensão da obra e não um condensado de decifração de signos que promovem um deslocamento no mapa da realidade. Nela o cenário tradicional da arte se desterritorializa: espaço, objetos, personagens (artista, espectador e crítico), modos de apresentação, de divulgação e de recepção da obra (Rolnik, 2002 p. 5). 


\subsection{Práticas estéticas e vida coletiva}

Assim, nos anos 1990, encontramos nos equipamentos implantados pelas políticas públicas de saúde mental (nos Centro de Atenção Psicossociais - Caps, nos Centros de Convivência e Cooperativas - Cecco) experiências artísticas e culturais que apresentam possibilidades de trabalhar a cultura da exclusão e da vivência da diversidade como desigualdade. As ações se dão em diferentes projetos: artesanais, grupos de teatro, murais da cidade, grupos de pintura, fotografia, oficinas de literatura, dança, entre outros. Artistas se unem a profissionais da saúde mental na sustentação de ateliês e oficinas de produção artística, vivências que potencializam e ampliam a experiência cultural e participam da desconstrução de preconceitos, valores, afetos, que tecem a representação social da loucura, favorecendo o envolvimento de pessoas com sofrimento psíquico em atos e fatos de cultura (Castro \& Silva, 2007).

Esse novo panorama gerou a necessidade de construir um trabalho que apresentasse uma melhora real da qualidade de oferta aos pacientes, com novas possibilidades de atividades que despertassem interesse, gosto, vontade de instrumentalização técnica, enfim, outros caminhos que não só a assistência específica ao diagnóstico, à "doença”, à falta. As múltiplas propostas nesse cenário identificaram uma série de necessidades da população atendida: de expressão pessoal, de comunicação, de conhecimento do corpo, de conhecimento das possibilidades da arte, de métodos e técnicas de instrumentalização nesses campos; necessidade de participação em grupos de atividades, de ampliação da compreensão e do reconhecimento de si e do mundo, de diálogo e apropriação da cultura, a partir de práticas vivenciais, de participação sociocultural (Castro, 2001).

Toda a busca de conhecimento de técnicas e metodologias de trabalho surgiu desse diálogo e da identificação dessas necessidades. Assim, os operadores de saúde mental que mergulharam nesse campo se tornaram interlocutores da população atendida, e as metodologias e os instrumentais técnicos eram selecionados para possibilitar um diálogo a partir das necessidades dos pacientes e da busca de sua autonomia pessoal e da cidadania. 
Arte e cultura passam a tocar dimensões éticas, técnicas, culturais e políticas, afirmando os direitos humanos dos pacientes psiquiátricos. Isto levou os operadores de saúde mental e a população atendida a um fértil campo de experiências relacionadas à expressão, à comunicação, à organização de linguagens, à apropriação de si mesmo. Experiências referentes aos produtos, à divulgação, às produções culturais e à diversidade. Vivências individuais e coletivas que ampliam nossa concepção de racionalidade para muito além das fronteiras tradicionais, auxiliando no processo de compreensão e transformação do mundo, e na constante criação e recriação da própria existência.

É importante abordar a necessidade de desenvolvimento das condições físicas, materiais e pessoais para esse trabalho: o espaço de trabalho (ateliê), os materiais (materiais técnicos simples são grandes recursos para começar) e a formação da equipe de trabalho são condições fundamentais, a base do estímulo criador e do consequente desenvolvimento de projetos individuais e coletivos. Também é essencial o cuidado com os produtos, no sentido de eles ganharem significações coletivas e serem articulados a uma rede de sustentação, ganhando valor para um grupo ou para alguém, podendo vir a criar novos territórios de trânsito e troca, assumindo e afirmando as diferenças que vão surgindo, mas fundamentalmente estabelecendo um diálogo entre as formas vigentes e as que vão sendo engendradas pelas novas práticas: exposições, festas, participação em eventos e feiras, enfim, experiências em espaços de maior liberdade, que permitam a construção de um novo cotidiano e ajudem na transformação cultural (Lima, 1997, p. 100).

Toda essa nova fase trouxe muitas práticas e também muitas dúvidas e questões. Surgiram estudos mais aprofundados, ora enfocando questões sobre a nova qualidade de oferta e de vida dos pacientes, ora sobre a criação e sua importância para a saúde, ora sobre a importância de transformar relações, cotidianos, tensões sociais e ambientes. O terapêutico, aqui, consiste em criar acesso, possibilitar a participação, formar a experiência em arte, ter o direito de circular na vida cultural, de produzir cultura. 
Trata-se de um amplo movimento no qual a experiência da alteridade mobiliza afetos e iniciativas, implicando sobretudo uma mudança da sensibilidade coletiva. Ampliam-se conceitos e práticas que ultrapassam o cenário terapêutico e ganham ações no território sociocultural, com participação, acesso, criação e formação em arte. Relações sociais, produção subjetiva e transformação dos ambientes são aspectos da multiplicidade de processos de tratamento com suas demandas singulares. Várias são as atividades e possibilidades artísticas, várias são as novas imagens que compõem a cena contemporânea:

Não há, e nem pode haver, na verdade, barreiras ao mundo encantado das formas; não há filas para entrar nesse recinto, que não é de ninguém, que é comum a todos os homens indistintamente. Feliz a humanidade quando todos eles, sem inibições e iniciados, puderem penetrar seu campo mágico! A iniciação está ao alcance de todos (Pedrosa, 1949, p. 166).

\section{Experiências contemporâneas}

Nos últimos 11 anos, nossa experiência na Universidade de São Paulo favoreceu práticas, formação e pesquisas que validam um campo de interfaces, em que esferas de conhecimento se interconectam e se cruzam para alimentar novas práticas e mobilizar na Terapia Ocupacional o desenvolvimento de novas tecnologias de cuidado e de participação sociocultural. Na perspectiva da construção de uma saúde mental ampliada e de intervenção sociocultural com as diferentes populações atendidas (crianças, adolescentes, adultos e idosos) e em situação de vulnerabilidade social, passamos a construir, além de um programa próprio de formação e assistência, uma articulação em rede entre vários projetos que se desenvolvem no território da cidade de São Paulo.

Diferentes linguagens artísticas vão, portanto, estabelecer relações com a construção do cotidiano, com a produção de subjetividades e com a renovação do território sociocultural para as populações em situação de vulnerabilidade social. 
Reconhecemos um deslocamento contemporâneo pelo qual a arte não consiste apenas na produção de obras, mas em produção de acontecimentos, ações e experimentações. Assim, aspectos da arte contemporânea dão às práticas elementos para a promoção de processos de vida e de criação. Novas configurações em rede, multiplicidade de ações, linguagens e formas de participação renovam os modos de trabalhar. Composições interdisciplinares abrem novas conexões, alargando direções para a produção da existência coletiva.

Privilegiamos os temas da arte, do corpo e da construção da participação social, por sua potência de invenção e por possibilitarem novas formas de vida. Trata-se de proporcionar conhecimento e experiência com outros recursos que concorrem para a transformação das rotinas e ordem estabelecidas e de oferecer às pessoas instrumentos para seu próprio uso, permitindo crescimento pessoal, autonomia, interação social e inclusão cultural. Esses temas têm pontos de confluência entre a necessidade de expressão humana e a constante construção da linguagem, transformando-se em veículos e campos de referência para a comunicação de cada um. O contato e a convivência com eles ensejam ressonâncias no desenvolvimento pessoal, na expressão da sensibilidade, na organização do cotidiano e nas relações interpessoais e possibilitam um diálogo com a cultura. São vivências e trabalhos que estabelecem conexões entre os momentos da vida de cada um e de sua interação com o mundo, favorecem experiências singulares e se configuram como possibilidades de conhecimento.

Criamos o Programa Permanente Composições Artísticas e Terapia Ocupacional, que se propõe a acompanhar grupos de atividades artísticas e compreender o fazer artístico, a atualização cultural e a divulgação das produções realizadas, atendendo grupos de crianças, de adolescentes e de adultos, e operando como lugar de formação e como extensão de serviços da Universidade à comunidade. A partir desta proposta, habitamos um território de fronteira, de natureza interdisciplinar, no qual práticas clínicas, educacionais, sociais e culturais, buscam garantir a participação destas pessoas num território de experimentação, criação e produção artística e cultural. Tem-se produção de saúde na atenção individual e 
coletiva para a melhora da qualidade de vida das pessoas atendidas; restaura-se a participação e a vida em comunidade, organizando diferentes modalidades de inclusão na trama sociocultural.

No acompanhamento de pessoas nessas atividades (e muitos deles têm longas histórias em atenção psiquiátrica), o terapeuta ocupacional precisa estar atento e numa disposição observadora e propiciar um contato pessoal poroso, com a qualidade e o acompanhamento de "um afeto catalisador", usando a expressão de Nise da Silveira. O cuidado com as relações interpessoais é um dos pilares da prática, em que a influência recíproca transforma todos os envolvidos. O cuidado com os vínculos e a organização dos ambientes expressivos favorece o processo formativo que a atividade artística pode disparar. No decorrer dos trabalhos, surgiu a necessidade de ampliar a experiência aos familiares e à rede social mais próxima, pois todos relatavam uma vida muito restrita. Ressonâncias de processos singulares abriam novos encadeamentos de necessidade de atenção à produção subjetiva.

Encontramos várias metodologias e formas de abordagem do corpo e da arte nessa interface. Num trabalho em composição, há trocas entre artistas, profissionais da saúde, educação e cultura. Nesse contexto, a formação em arte e a atenção ao próprio processo de fruição criativa ajudam a acompanhar a complexidade da vida dos participantes e a dar sustentação aos projetos em arte.

No que concerne a essas atividades, a principal marca da Terapia Ocupacional é não se limitar a uma aproximação teórica, mas principalmente vivênciá-las - desenhar, pintar, esculpir, fotografar, filmar, dançar, atuar, construir objetos, viver o corpo, ouvi-lo, estar atento, perceber sua linguagem, desenvolver cuidados -, estudá-las, incorporá-las.

O contato com o corpo e a arte geram um estado de excitação e ressonância mentais extremamente favoráveis ao trabalho criativo. São atividades catalisadoras do processo terapêutico que imprimem qualidade à vida das pessoas. Nesse sentido, a atividade humana se recria e na sua ação prática há uma fusão sincrética, uma reunião de várias instâncias trabalho, conhecimento, comunicação e orientações valorativas -, o que 
dá uma visão de conjunto de uma experiência complexa (Kagan, 1987 in Castro, 2001).

As parcerias com outros projetos trouxeram uma nova perspectiva de atuação para os terapeutas ocupacionais, na composição interdisciplinar e no preparo do território no sentido relacional, ambiental e no olhar atento aos processos singulares. Por exemplo, no Museu de Arte Contemporânea da USP, fizemos parceria com o Programa Lazer com Arte para a Terceira Idade e o Projeto o Museu e o Público Especial. A presença dos terapeutas ocupacionais num museu de arte, ajudando na construção de propostas para a população e na prática da inclusão social, são novas marcas da acessibilidade. Outros projetos de atenção e formação derivaram desse encontro. A questão agora é reabilitar os espaços vividos, os territórios da cidade (Venturini, 1999). Nossa inserção em projetos na área da cultura tornou cada parceria estabelecida um campo fecundo de novas produções e da reafirmação do enfrentamento desse problema. A principal conquista foi a participação de pessoas em situação de vulnerabilidade social e de experiência da diferença em equipamentos culturais com grande potencial de difusão e fruição artística. Por composições híbridas entre educadores, artistas e terapeutas ocupacionais, delineou-se uma nova gama de experiências e projetos potentes.

São projetos artísticos que precipitam acontecimentos. Evidenciam a força criadora e vital. São fundamentais para as pessoas, em especial aquelas que vivem intenso sofrimento psíquico e que precisam encontrar outro meio de comunicação, para as quais os meios intelectuais ou discursivos não são suficientes. Aos poucos, essas experiências vão se tornando vitais para aqueles que precisam de gestos ou outras formas de expressão que estabeleçam pontes de comunicação com o mundo, que possibilitem a expressão de sentimentos, numa nova organização do cotidiano e numa participação real na cultura.

Assim, arte, corpo e cultura são temas concebidos em bases amplas, formando um sistema aberto que não cerra portas a possíveis descobertas. Nesses campos, há um devir de retorno lento a si mesmo, de descoberta de sua própria singularidade, de fortalecimento da existência e de expansão da vida. 
Neste tempo de necessidade de renovação e transformação da clínica, da ciência, das relações interpessoais e da própria cultura, vislumbramos uma nova perspectiva de construção da participação social. Para isso, temos estudado esses campos, suas metodologias e abordagens e construído práticas na interface da Arte e da Saúde. Sabemos que o importante nesse processo é a existência de projetos que favoreçam a experiência criativa, que sejam alternativas sociais e propiciem qualidades humanas: tolerância, paciência, expressão, comunicação, vontade de fazer, e de fazer cada vez melhor, com qualidade e atenção ao corpo e ao processo de fruição criativa. Esses são fatores que fundamentam o trabalho nessa interface.

Nesse processo, há a emancipação cultural do próprio terapeuta, para que sua clínica pertença à contemporaneidade e, nesse sentido, ajude seu paciente a conviver nela. Muitas vezes, o aprofundamento nesses temas traz um desconforto, um incômodo que desestabiliza o sistema de conhecimento e de práticas instituídas, que rompe com a normatização e estabelece o diálogo com o fora. Nesse aspecto, há duas proposições: uma de liberação da expressão - deixar falar aquele que na sua história pessoal ou clínica não foi ouvido - e outra de transformação do sistema social e cultural, com a inclusão de outras formas de expressão, entendimento e compreensão, registro e experiências singulares. Isso significa construir uma sociedade múltipla, enriquecida por cada um dos seus membros.

\subsection{Os ateliês de corpo e arte em terapia ocupacional: dispositivos de ação, produção de vida e de participação sociocultural}

O trabalho num grupo de adultos (2001-2008) favoreceu uma experiência singular no acompanhamento direto da população e na observação das mudanças que a participação e o pertencimento aos ateliês imprimiram à sua vida. Trabalhos grupais e individuais caracterizaram essa proposta de atenção, pautada em procedimentos que articulam atividades artísticas e corporais ao campo da Terapia Ocupacional. Heterogéneo, formado por 16 pessoas, todas com marcas da vulnerabilidade social, o grupo foi acompanhado inicialmente por cinco anos; depois desse período, confi- 
guramos um projeto de exposições e o efetivamos em mais dois anos de trabalho, ao fim dos quais identificamos novas configurações e agrupamentos e novos desejos de continuidade. Optamos por continuar com os mais graves, pois os outros tinham já estabelecido redes de convivência em torno do próprio interesse e da pesquisa artística. Constelou-se uma multiplicidade de variantes.

Aprofundaram-se os estudos e o desenvolvimento de práticas do corpo e da arte articuladas ao campo da Terapia Ocupacional; houve acompanhamento e relato da mudança na disposição geral de cada participante - uma nova vitalidade, mais disposição de participação e resolução de problemas em sua vida e mais permeabilidade à construção de vínculos. Mudaram seu cotidiano e sua vida; dinamizaram-se os processos socioculturais em função de sua participação no trabalho de inserção da produção artístico-cultural e no cuidado com essa produção.

Essa experiência confirmou a necessidade de propostas que recuperem a dimensão criativa da vida humana e sua reconexão com ritmos que permitam uma integração pessoal e ambiental, pelo cuidado e pela atenção necessários à vida na contemporaneidade. A organização e (re) estruturação do campo das atividades humanas não desconsiderar o fator criativo, a corporeidade e a produção de subjetividade relacionados à experiência singular de cada sujeito. Os participantes foram cuidados num meio cuja abrangência da linguagem instaurou um processo cognitivo, de participação social, ampliação das experiências e reconhecimento de si, revitalização da participação sociocultural criando novas atitudes frente à vida. Além de muitos pequenos detalhes que nos marcaram e que são ricos em significação e trocas.

Identificamos aí a formatividade artística e corporal. Estabelecemos relações entre a experiência humana e as formas de arte, em cuja multiplicidade cada um estabelece as regras pelas quais espera reconhecer seu mundo. A obra abre um espaço de experiência em que se articulam paradoxal e constitutivamente o sujeito e o mundo (Frayze-Pereira, 2005, p.48).

Para Pareyson (1984), a arte pode ser entendida como fazer, como exprimir e como conhecer. São concepções que ora se opõem, ora se 
combinam, mas que, grosso modo, apontam contextos históricos distintos. A formatividade é um conceito em arte e também no campo corporalista (Favre, 2004; Keleman, 1992; Keleman, 1995) e com este conceito podemos acompanhar crescimentos bem sutis, bem delicados.

\section{Considerações finais}

Na contemporaneidade, vemos práticas estéticas construídas na interface da arte e da saúde que abrem pensamentos e reflexões e propiciam novos contatos. Às vezes, essas produções nos parecem estranhas, precárias, feitas de materiais pobres e muito simples. A impressão é de que estamos distantes não só da concepção clássica de arte - do que habitualmente entendemos como objeto de arte -, mas também de muitas práticas estéticas da atualidade. Isto nos remete a muitos questionamentos, mas enfim, o que pode a arte? E caminhando um pouco mais, o que pode a arte de um louco, de populações excluídas do eixo dominante?

Toda criação verdadeira é um processo de autoconstituição. Mas, se há possibilidade de expressão, se se tenta detectar os signos que emergem, mesmo os mais efêmeros, o que vai ser produzido, o que vai se autocriar é algo que tem uma tendência não a se fechar, mas a fazer com que haja "aberto". [...] o que está em questão é um processo de criatividade que é, ao mesmo tempo, um processo de "reconstrução de si mesmo" (Ocupação UEINZ, 2009).

Acompanhamos muitas histórias de sofrimento psíquico. Pessoas com diferentes registros da experiência de viver no mundo. Pessoas que vivem situações extremas (seja de pobreza, violência, desorientação ou impossibilidade de compreensão da vida urbana contemporânea), mas que sobrevivem às várias destruições. São sobreviventes. Sobrevivente é um termo com que se vem designando pessoas que passaram por situações-limite e que parece melhor caracterizar aqueles que criativamente 
driblam óbices mortíferos da contemporaneidade. Instauramos com cada um deles um contato inimaginável (Ocupação UEINZ, 2009).

Construímos pontes, criamos alguns “enxertos de abertura”. Coisas mínimas, nas palavras de Oury (2009). E também nem tanto, pois, ao se conectar com suas forças de criação, veem surgir as aberturas e a vida com os outros, uma vontade de formar, entre a arte e a vida. Transformar os processos da arte em sensações de vida: esse foi o desígnio, explícito ou não, que atravessou o trabalho das vanguardas, mobilizando o pensamento e muitas das ações empenhadas na transmutação da arte e que continua ativo na atividade artística contemporânea, tensionando as relações entre os dois termos (Ocupação UEINZ, 2009).

O contato com a não cultura e a inserção da não arte no circuito cultural instituíram uma série de marcos simbólicos na discussão de questões estéticas, provocando deslocamentos e articulações. Deambulação, devir e simpatia favoreceram a continuidade e a múltipla adesão. Trata-se de mostrar como a relação com outrem se constrói por uma necessária deambulação que nos leva até a vizinhança dos signos emitidos por ele. Essa deambulação é crucial e aciona a simpatia (Lapoujade, 2009)

Por fim, o que temos acompanhado com alegria é o surgimento das políticas culturais desenvolvidas pelo Ministério da Cultura (Brasil, 2005), com incentivo para projetos que se constituem na interface arte e saúde para essas populações, e as políticas públicas de humanização do Ministério da Saúde (Brasil, 2003), que se preocupam cada vez mais com a saúde e com as pessoas, no enfrentamento diário das cristalizações do poder. Enfim, esperamos seguir formando novos cenários de vida e de participação coletiva.

\section{Referências bibliográficas}

Brasil. Ministério da Cultura. Programa Cultura Viva. Brasília: Ministério da Cultura, 2005. Disponível em: http://www.cultura.gov.br/cultura_viva/.

Brasil. Ministério da Saúde. Humaniza SUS: Política Nacional de Humanização. Brasil. Ministério da Saúde. Secretaria-executiva. Núcleo Técnico da Política Nacional de Humanização. Brasília: Ministério da Saúde; 2003. Disponível em: http://www.bvs.saude. gov.br/bvs/publicações_2004.pdf 
CASTRO, E. D. (2001). Atividades Artísticas e Terapia Ocupacional: criação de linguagens e inclusão social. São Paulo, ECAlUSP, Tese de doutorado.

CASTRO, E. D. \& Lima, E. M. F. DE A. (2007). Resistência, Inovação e Clínica no pensar e no agir de Nise da Silveira. Interface: Comunicação, Saúde e Educação, v.11, 35-49.

CASTRO, E. D. \& SILVA, D. M. (2007). Atos e fatos de cultura: territórios das práticas, interdisciplinaridade e as ações na interface da arte e promoção da saúde. Rev. Ter. Ocup. Univ. São Paulo. vol. 18, n. $^{\circ} 3,102-112$.

FAVRE, R. (2004). Viver, pensar e trabalhar o corpo como um processo de existencialização contínua. Revista Reichiana, Instituto Sedes Sapientae, n. ${ }^{\circ} .13$.

Frayze-PEReIrA, J. A. (1995). Olho d'água: arte e loucura em exposição. São Paulo: Escuta \& Fapesp.

FrAYZe-PEReIra, J. A. (2005). Arte, Dor. Inquietudes entre Estética e Psicanálise. São Paulo: Ateliê Editorial.

HIDAlgo, L. (1996). Arthur Bispo do Rosário: O senhor do labirinto. Rio de Janeiro: Rocco.

KAGAN, M. (1987). El Arte en el sistema de la actividad humana. In: Estética, selección de lecturas. La Habana: Editora Pueblo y Educación.

Keleman, S. (1992). Anatomia Emocional. São Paulo: Summus.

Keleman, S. (1995). Corporificando a experiência. São Paulo: Summus.

Lapoujade, D. (2009). Deambulação, Devir, Simpatia. In: Ocupação UEINZ, São Paulo [Palestra]. São Paulo: SESC Paulista.

LIMA, E. M. F. DE A. (1997). Terapia Ocupacional: um território de fronteira? Rev. Ter. Ocup. Univ. São Paulo; 8 (2-3), 98-101.

Ocupação UEINZ (2009). Mostra de espetáculos teatrais, filmes e conferências que discutem o deslocamento entre clínica, arte e política na contemporaneidade. São Paulo: SESC Paulista.

OURY, J. (2009). O coletivo. São Paulo: Aderaldo\&Rotischild.

PALATNIK, A. (2000). Catálogo Museu de Imagens do Inconsciente. Mostra do redescobrimento. São Paulo: Associação Brasil 500 anos Artes Visuais. (Catálogo - Fundação Bienal de São Paulo).

PAREYSON, Luigi (1984). Os Problemas da Estética. São Paulo: Martins Fontes.

Pedrosa, M. (1949). Arte, necessidade vital. Rio de Janeiro: Casa do Estudante do Brasil.

ROLNIK, S. (1996). Lygia Clark e o híbrido arte/clínica, Percurso - Revista de Psicanálise, Ano VIII, n. ${ }^{\circ} 16$ (43-48), 1o semestre de 1996. São Paulo: Departamento de Psicanálise, Instituto Sedes Sapientiae.

ROLNIK, S. (2002). Alteridade e Cultura: arte cura? Lygia Clark no limiar do contemporâneo. In: G. Bartucci (org.), Psicanálise, Arte e Estéticas de Subjetivação. Rio de Janeiro: Imago.

SARACENO, B. (1995). La fine dell' intrattenimento: manuale di riabilitazione psichiatrica. Milano, ETASLIBRI/RCS Medicina.

SILVEIRA, N. (1981). Imagens do inconsciente. Rio de Janeiro: Alhambra.

Silveira, N. (1986). Casa das Palmeiras: a emoção de lidar. Rio de Janeiro: Alhambra.

SILVEIRA, N. (1992). O mundo das imagens. São Paulo: Ática.

SIlveira, N. (s/d). Terapêutica ocupacional: teoria e prática. Rio de Janeiro: Casa das Palmeiras. Museu de Imagens do Inconsciente. Disponível em: htpp://www.museuimagensdoinconsciente.org.br

Venturini, E. (1999). A Reabilitação e a Vida na Cidade. Conferência proferida na Escola de Enfermagem da USP, Outubro. 